\title{
Faecal corticosterone metabolite assessment in socially housed male and female Wistar rats
}

\author{
Carlo Cinque 1,2, Manuela Zinni², Anna Rita Zuena², Chiara Giuli', Sebastiano G Alemàㄹ , Assia Catalani², \\ Paola Casolini ${ }^{2}$ and Roberto Cozzolino ${ }^{1}$
}

${ }^{1}$ Fondazione Ethoikos, Radicondoli, Italy

${ }^{2}$ Department of Physiology and Pharmacology V. Erspamer, Sapienza University of Rome, Rome, Italy

Correspondence should be addressed to C Cinque: carlo.cinque@ethoikos.it

\begin{abstract}
Knowledge of animals' hormonal status is important for conservation studies in wild or semi-free-ranging conditions as well as for behavioural and clinical experiments conducted in laboratory research, mostly performed on rats and mice. Faecal sampling is a useful non-invasive method to obtain steroid hormone assessments. Nevertheless, in laboratory studies, unlike other contexts, faecal sampling is less utilised. One of the issues raised is the necessity to collect samples belonging to different animals, separately. Usually, researchers using faecal sampling solve this problem through the isolation of animals or taking the cage rather than single animal as unit of study. These solutions though, could lead to unreliable measurements, and cannot be applied in many studies. Our aim was to show the biological reliability of individual faecal corticosterone metabolite (FCM) assessments in socially housed male and female Wistar rats. We analytically validated the enzyme immunoassay kit used for FCM assessments. Then, we exposed the animals to two different stress stimuli that are known to activate the hypothalamus-pituitary-adrenal axis and the following release of corticosterone to biologically validate the EIA kit: environmental enrichment and predator odour. Individual faecal sampling from social animals was collected through short-time handling. The results demonstrated that both the stimuli increased FCM levels in male and female rats showing the reliability of EIA kit assessment and the applicability of our sampling method. We also found a diurnal rhythm in FCM levels. These results could help to increase the use of faecal hormone metabolite determinations in studies conducted on rats.
\end{abstract}

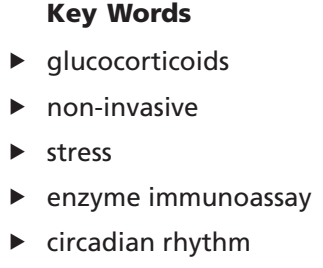

Endocrine Connections (2018) 7, 250-257

\section{Introduction}

Stress events can have an important impact on both physiological and psychological parameters. For this reason, assessing animals' stress physiology is essential to understand and improve animal welfare, health and reproduction (1). For ethical and experimental reasons, a growing number of researchers tend to use non-invasive techniques for steroid hormone level assessments in wild and captive vertebrates $(2,3,4,5)$. Among the noninvasive matrices, the faeces are the most used (6). Instead, in laboratory animal research, mainly performed on rats and mice, most of the studies still report data from blood sampling. In fact, faeces were used for measurements of corticosterone levels in rats and mice, in about 150 out of 7000 studies conducted from 2000 until present. Blood analysis is undoubtedly powerful, allowing instantaneous determination of steroid and peptide hormone levels as well as many other physiological parameters not available in faeces; however, this kind of assessment could be
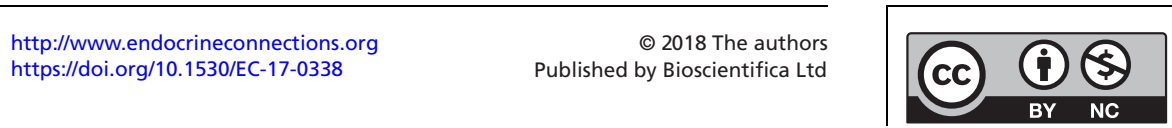

This work is licensed under a Creative Commons Attribution-NonCommercial 4.0 International License. 
influenced by events, often unknown to experimenters, that took place immediately before sampling. This is particularly important for glucocorticoid hormones. Furthermore, in most cases, blood withdrawal requires handling and restraint of the animals, with a consequent activation of the hypothalamic-pituitary-adrenal (HPA) axis that quickly leads to secretion of glucocorticoids (7).

For some experimental designs, faecal sampling may be a valid non-invasive method for steroid hormone assessment in laboratory mice and rats. Faeces are easy to collect and allow to estimate only the 'free' unbound fraction of glucocorticoids that is biologically active and available for target cells and consequently for metabolism. It is known that, in mice and rats, a high percentage of steroid metabolites are excreted via faeces in comparison with other matrices $(1,6,8)$. Faeces provide an averaged measure of hormone levels related to a time window depending on intestinal transit time. Thus, the measure is less affected by short-time events that take place before sampling. However, faecal hormone metabolite assessment presents some drawbacks as well. In order to obtain hormonal determination for each animal, necessary in most studies, researchers usually isolate the animals in standard or metabolic cages (e.g. 9, 10, 11). Isolation allows an easier collection of the faeces, but it has been demonstrated to induce an increase of corticosterone levels with respect to animals housed in standard cages, in groups of two-three per cage $(12,13)$. Wild mice and rats live in social groups characterised by complex dominance systems. It has been shown that mice prefer social to physical environmental enrichment (EE) (14). They choose to share a common sleeping site and usually sleep close together regardless of social status (15). For these reasons, solitary housing can be considered a stressor in social species (16), and it can deeply modify the behavioural and hormonal profile of animals (17). Thus, it could be useful to leave the animals in standard social condition during faecal sampling, to obtain more accurate and reliable measurements in laboratory rodents. The aim of our study was to set up a faecal sampling method involving short time handling, for steroid hormone assessment in male and female Wistar rats housed in standard social condition. We focused our research on faecal corticosterone metabolite measurements. We utilised a commercial enzyme immunoassay (EIA) kit employed for faecal corticosterone metabolite (FCM) assessments in rodent species $(18,19,20)$. The EIA kit was tested for analytical accuracy as no bibliography of its use was available for rats. Beside this, it was also necessary to physiologically or biologically validate the

$$
\text { http://www.endocrineconnections.org }
$$

immunoassay used for faecal hormone measurements to test the reliability of the results found $(21,22)$. In order to evaluate the biological reliability of FCM levels assessment obtained through the chosen EIA and the applicability of our faecal sampling method, we exposed the animals to the following challenge events: (i) novel physical and social environmental enrichment (EE) $(23,24)$ and (ii) predator odour. In fact, it is known that the exposure to EE (25) or to the odour of a phobic stimulus such as predator scent (26) induces an increase of plasma corticosterone concentrations in rats. We also assessed FCM circadian rhythm in socially isolated male and female rats in order to verify the presence of corticosterone circadian secretion as it can be observed by means of blood sampling (27).

\section{Materials and methods}

\section{Animals}

Ten male and 10 female 10-week-old Wistar rats (Charles River) were housed in same-sex groups of two to three animals in makrolon type III cages $(430 \times 230 \times 150 \mathrm{~mm})$ with saw dust floor, in standard conditions (controlledtemperature room, $21-23^{\circ} \mathrm{C}$; humidity $40-50 \%$; $12: 12-\mathrm{h}$ day/night cycle, light on 07:00). Food (Standard Diet Charles River 4RF21) and water were available ad libitum. After one week, same-sex animals were housed five per cage, for three consecutive days (72h), in environmental enriched cages $(65 \times 62 \times 41 \mathrm{~cm})$ equipped with two floors connected by a ladder (PRS Italia, Rome, Italy). The cages contained wood shavings, a $25-\mathrm{cm}$ running wheel and a shelter tunnel. Moreover, each cage was supplied with three objects different from each other in shape, odour and material: a coloured plastic ball, a wooden cube and some nesting materials (paper). These were moved every day to maintain the novelty of the environment. At the end of the EE exposure, the rats were brought back to their original cage, two to three per cage, in the standard condition, and left undisturbed for at least two weeks. The animals were then singly exposed to predator odour (bedding contaminated by male cat urine) for $15 \mathrm{~min}$. At the end of the stress event, the animals were moved again to their social cages.

Another group of 9 male and 9 female 10-week-old Wistar rats (Charles River) were used for FCM circadian rhythm assessment. On arrival, the animals were singly housed in makrolon type III cages in standard condition with food and water ad libitum. They were left undisturbed for at least one week.

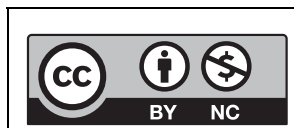
This work is licensed under a Creative Commons
Attribution-NonCommercial 4.0 International License. 
The number of animals selected was considered more than reasonable to perform statistical analysis and obtain reliable results.

All procedures were approved by the Italian Ministry of Health (Rome, Italy) prior to the new legislation and performed in agreement with the guidelines of the European Convention for the Protection of Vertebrate Animals (CEE n. 609/86) and the Italian Ministry of Health (D.L. 116/92), under the supervision of the local animal welfare body of the faculty where the experiments were carried out.

\section{Sample collection}

Each animal was gently removed from its cage with the aid of a towel and was briefly handled (less than $2 \mathrm{~min})$ to stimulate the release of faecal boli that were immediately stored at $-20^{\circ} \mathrm{C}$. For EE experiment, basal level samples were collected in the late morning, $24 \mathrm{~h}$ before the exposure to EE. After the exposure, two more faecal samples were collected, 24 and $72 \mathrm{~h}$ later, when the animals were still in the EE cages. Similarly, for the predator odour stress test, basal faecal samples were collected from each rat in the afternoon of the day before the exposure to cat odour (at the same time of the day in which the post-stress samples were collected). The stress exposure test was performed at 09:00 the following day; 6 and $8 \mathrm{~h}$ after the end of the stress exposure two post-stress samples were collected. As only one of the two samples required for each sampling period was collected for some animals, basal and post-stress samples were respectively pooled. In a few cases, some animals were excluded from the analysis because of impossibility to collect their faecal samples. The number of animals used is reported in the results section.

For FCM circadian rhythm evaluation, one week after the arrival of the animals, all faeces were removed from each cage at 08:00. Following this, faeces were collected every $12 \mathrm{~h}$ for two consecutive days.

\section{Sample preparation}

Each frozen sample was mixed with a mill (A11, IKA, Germany). An aliquot of $0.1 \mathrm{~g}$ was transferred in a glass tube and $3.7 \mathrm{~mL}$ of ethanol $96 \%(\mathrm{v} / \mathrm{v})$ were added to the sample. The sample was then homogenized (Ultraturrax, IKA, Germany), shaken at $700 \mathrm{rpm}$ in the mixer evaporator (Glasscol) for $45 \mathrm{~min}$ at $85^{\circ} \mathrm{C}$ and centrifuged at $500 \mathrm{~g}$ for $10 \mathrm{~min}$ at $10^{\circ} \mathrm{C}$. The supernatant was collected. In order to recovery steroids still present, the residual pellet was suspended again in ethanol 96\%, shaken for $10 \mathrm{~min}$ at $45^{\circ} \mathrm{C}$ and centrifuged as described earlier; the two supernatants were combined and evaporated under warm air flow $\left(80^{\circ} \mathrm{C}\right)$. Steroids were suspended with $750 \mu \mathrm{L}$ of absolute ethanol and shaken again at $45^{\circ} \mathrm{C}$ for $45 \mathrm{~min}$. The faecal extract was transferred in vials with caps and kept at $-20^{\circ} \mathrm{C}$ until hormonal assay.

\section{Enzyme immunoassay}

FCM levels were quantified using a commercial EIA kit for corticosterone (KO14, Arbor Assays, Ann Arbor, MI, USA). Cross-reactivity of the corticosterone antibody was: $100 \%$, corticosterone; $12.30 \%$, desoxycorticosterone; $0.76 \%$, tetrahydrocorticosterone; $0.62 \%$, aldosterone; $0.38 \%$, cortisol; $0.24 \%$, progesterone; $0.12 \%$, dexamethason; $<0.1 \%$ with cortisone and estradiol.

The sensitivity of the assay was $139.5 \mathrm{pg} / \mathrm{g}$ and the corticosterone standard curve ranged from 0.6 to $75.0 \mathrm{ng} / \mathrm{g}$. Samples dilution and standard calibrators were prepared following kit instructions. Faecal samples were assayed in duplicate and reanalysed if the coefficient of variation exceeded 10\%. Assay data were analysed employing a four-parameter logistic fit using Gen5 Data Analysis Software (Biotek), and concentrations were expressed as $\mathrm{ng} / \mathrm{g}$ of faecal matter.

\section{Enzyme immunoassay analytical validation}

We evaluated the analytical accuracy of FCM levels assessment of male and female Wistar rat faecal samples. ANCOVA and analysis of linear regression were used to test whether pool of male or female faecal extracts diluted from 1:21 to $1: 1344$ were parallel to dilution series of corticosterone standards. The lack of a significant effect in ANCOVA (males $F_{(1,11)}=1.62, P=0.229$; females $F_{(1,11)}=1.72$, $P=0.216$ ) is a proof of parallelism of the three curves. The analysis of the three linear regression statistics corroborated ANCOVA analysis: standard curve $y=-36.83 x+149.0$, $r^{2}=0.98 ; \quad$ males' curve $y=-38.51 x+159.8, \quad r^{2}=0.99$; females' curve $y=-42.21 x+162.4, r^{2}=0.99$. The slope of standard curve had a standard error of 6.38 , while males' and females' slopes had a standard error of 4.79 and 4.29 respectively; thus, the observed difference between the coefficients was well inside the confidence interval. The intra-assay coefficient of variation of high and low concentrated quality controls ranged between $3.6 \%$ and 4.9\% (5 samples for male and female samples each assessed in 16 wells) while inter-assay coefficient of variation ranged between $6.4 \%$ and $9.9 \%$ (5 samples for male and female samples in duplicate in 8 plates). These results http://www.endocrineconnections.org https://doi.org/10.1530/EC-17-0338
(C) 2018 The authors Published by Bioscientifica Ltd
This work is licensed under a Creative Commons Attribution-NonCommercial 4.0 International License. 
show the analytical reliability of the EIA kit used for FCM measurements in male and female rats.

\section{Statistical analysis}

FCM levels during EE exposure, predator odour test and circadian rhythm were analysed by repeated analysis of variance (ANOVA) with sex as independent factor and period of sampling as repeated measures. The analysis was followed by a post hoc Bonferroni/Dunn test, where appropriate. Basal and stress FCM levels between the two challenge experiments were analysed by Student's $t$-test.

\section{Results}

Enzyme immunoassay biological validation and applicability of sampling method

\section{Exposure to environmental enrichment}

FCM levels significantly increased after the exposure to a social and physical EE in male and female rats $\left(F_{(2,24)}=6.18\right.$, $P=0.007$; males $n=7$, females $n=6$, ANOVA repeated measures), (Fig. 1) with similar trend in males and females (interaction sex ${ }^{*}$ period of sampling $F_{(2,24)}=0.25, P=0.785$, ANOVA repeated measures). The increased FCM levels were near to significance after $24 \mathrm{~h}$ and became statistically significant $72 \mathrm{~h}$ post exposure $(P=0.055, \quad P=0.002$, respectively, post hoc Bonferroni/Dunn test). Overall,

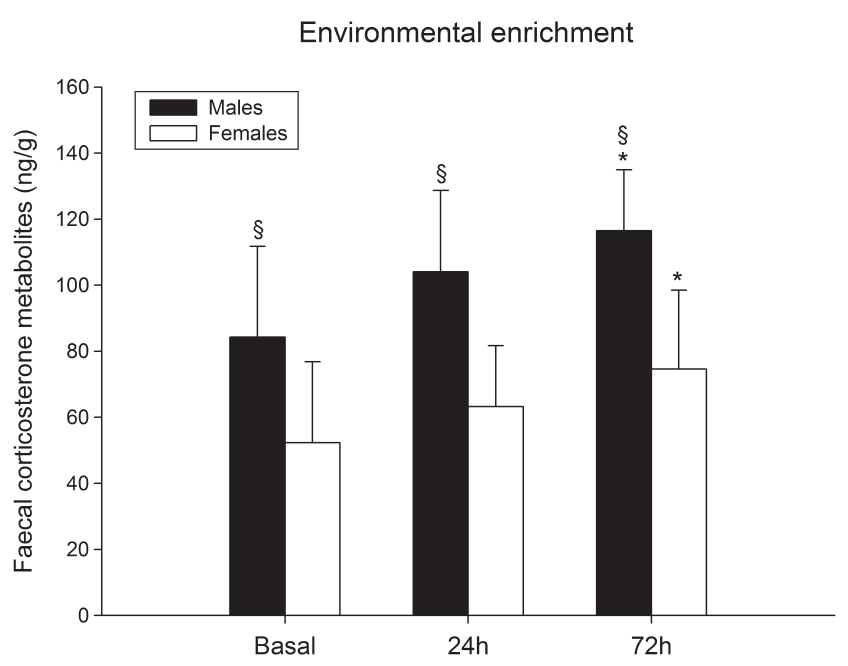

Figure 1

Mean ( \pm S.D.) faecal corticosterone metabolite levels in basal condition and $24 \mathrm{~h}$ and $72 \mathrm{~h}$ after the exposure to enriched environment of male $(n=7)$ and female $(n=6)$ rats. ${ }^{\star} P=0.007$ vs basal values; ${ }^{\S} P=0.002$ vs female rats, ANOVA repeated measures.

$$
\text { http://www.endocrineconnections.org }
$$

\section{Predator odour stress}

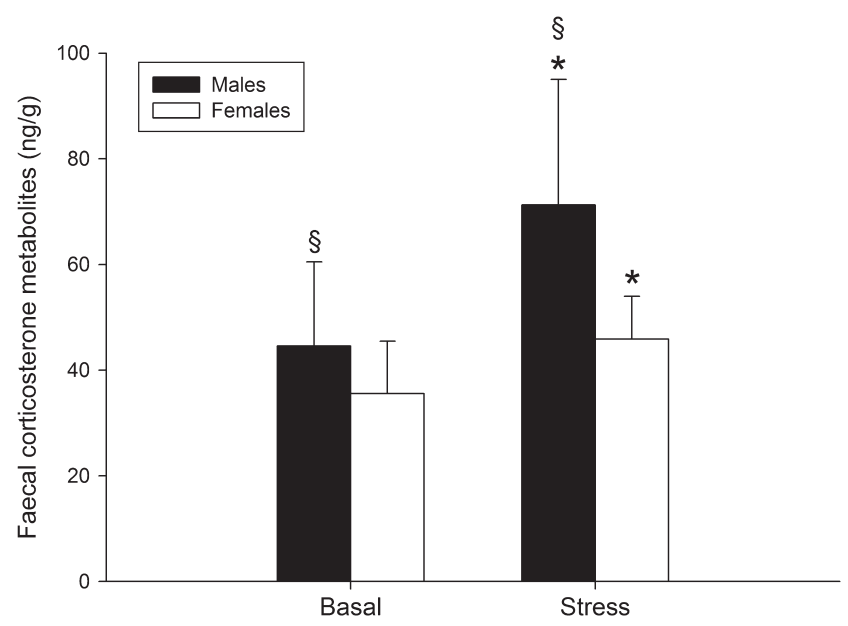

Figure 2

Mean ( \pm S.D.) faecal corticosterone metabolite levels in basal condition and after the exposure to the predator odour in the stress test of male $(n=9)$ and female $(n=9)$ rats. ${ }^{*} P=0.001$ vs basal values; ${ }^{\S} P=0.009$ vs female rats, ANOVA repeated measures.

male rats showed higher FCM levels compared to females $\left(F_{(1,12)}=17.06, P=0.002\right.$, ANOVA repeated measures $)$.

\section{Exposure to predator odour}

Male and female rats showed significantly increased FCM levels compared to their basal concentrations, after the exposure to the bedding contaminated by male cat urine $\left(F_{(1,17)}=15.94, P=0.001\right.$; males $n=9$, females $n=9$, ANOVA repeated measures), (Fig. 2 ) with similar trend in both sexes (interaction sex ${ }^{*}$ period of sampling $F_{(1,17)}=3.14, P=0.10$, ANOVA repeated measures). Overall, male rats showed higher FCM levels compared to females $\left(F_{(1,17)}=8.93\right.$, $P=0.009$, ANOVA repeated measures).

\section{Basal and stress FCM levels: comparison of environmental enrichment and predator odour experiments}

In general, the FCM levels were higher in EE exposure experiment compared to concentrations found in predator odour, both for basal and stress samples, in both males $(T=3.634, P=0.003 ; T=4.149, P=0.001$, respectively, Student's $t$-test) and females ( $T=1.861$, $P=0.086, \quad T=3.392, \quad P=0.005, \quad$ respectively, Student's $t$-test). However, when we compared the delta increase of FCM levels following to stress exposure we did not find any difference between the two experiments, both in male and female rats $(T=0.435, P=0.671 ; T=1.497$, $P=0.158$, respectively, Student's $t$-test).

This work is licensed under a Creative Commons Attribution-NonCommercial 4.0 International License. 


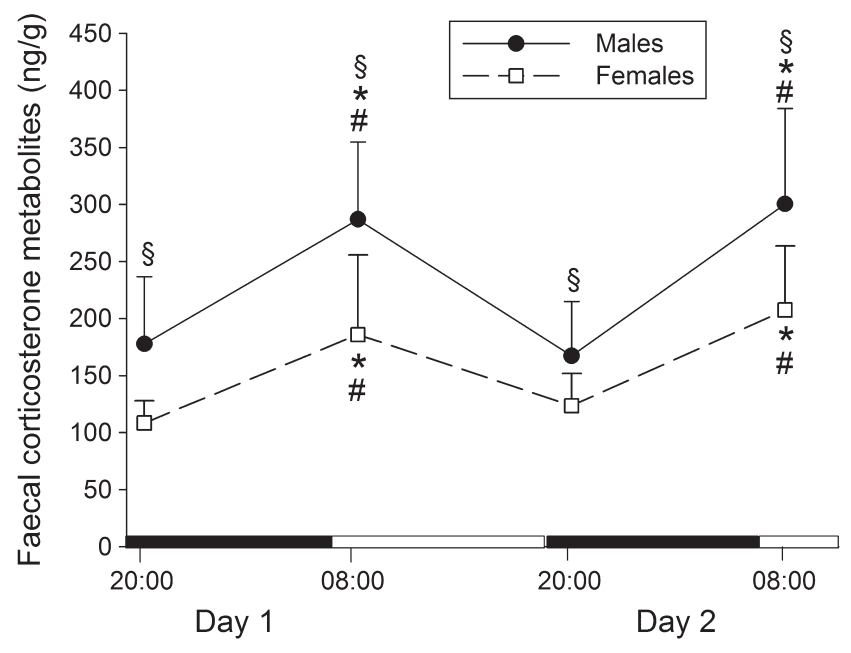

Figure 3

Mean ( \pm S.D.) faecal corticosterone metabolite levels circadian variation during the dark/light cycle of male $(n=9)$ and female rats $(n=9)$. The black areas in the abscissa indicate the dark periods and the white areas the light periods. ${ }^{*} P<0.001$ vs day 1 dark phase; ${ }^{\#} P<0.001$ vs day 2 dark phase; ${ }^{\S} P=0.03$ vs female rats, ANOVA repeated measures followed by post hoc Bonferroni/Dunn test.

\section{FCM circadian rhythm}

Lower corticosterone metabolite levels were found in samples collected at 20:00 and higher levels in those collected at 08:00, for both male and female rats (Fig. 3), $\left(F_{(3,51)}=39.13, \quad P<0.001\right.$, ANOVA repeated measures). Furthermore, higher faecal corticosterone metabolite levels were recorded for male rats compared to females $\left(F_{(1,17)}=12.42, P=0.003\right.$, ANOVA repeated measures $)$.

\section{Discussion}

This study showed the biological reliability of FCM assessment obtained through the commercial EIA kit used and, at the same time, the applicability of our faecal sampling method in socially housed male and female Wistar rats.

In order to avoid animal isolation, we chose to use the shortest handling time possible to collect the faeces. Therefore, some of the animals could not be sampled in all the scheduled intervals. These were excluded from the analysis. Nevertheless, the number of animals sampled was large enough to obtain reliable results. In fact, we had a high success rate in collecting faecal samples in both the challenge experiments, with no differences between male and female rats (60-70\% in EE and 90\% in predator odour exposure). Considering the lower success rate of the EE experiment, to be on the safe side, we suggest a slight increase in the number of animals used for sampling. Nevertheless, the number of animals needed to perform the experiment would, in any case, be lower in comparison with hormonal studies carried out through blood sampling, because this non-invasive method allows to perform repeated sampling.

Male and female Wistar rats exposed to a novel social and physical EE showed a trend to increased faecal corticosterone metabolites after $24 \mathrm{~h}$ of exposure to EE, which became statistically significant at the sampling point of $72 \mathrm{~h}$. This timing concurs with findings obtained for different species, through plasma (25) and urine (28) assessments. The exposure to EE generally requires a long-time exposure to induce a HPA axis modification. In fact, EE represents a chronic mild stress that should mediate the positive effects of increased levels of corticosterone; rats in EE are exposed to more stimuli, in quantity and diversity, than rats in standard cages, which presumably causes intermittent hormonal activation in a physiological way (25).

Cat's urine is an aversive stimulus that lasts the time of the exposure, thus representing an acute stress that could be more difficult to be detected through faecal hormone assessment because of its short time duration. This gave us the opportunity to test the efficacy of our faecal sampling method also in this condition. The exposure to saw dust contaminated by male cat urine resulted in increased FCM levels in both sexes, with respect to their basal values. According to studies on this topic $(29,30)$, we also qualitatively observed an increased freezing behaviour of animals during the exposure to cat's urine.

In literature contrasting results are reported about the estimation of intestinal transit time for rats, with quite a large excretion time window, i.e. between 6 and $24 \mathrm{~h}(8,31,32)$. These results can be, at least partially, explained by some factors that differ among literature data, i.e. age of the animals, strains, frequency and time of sampling $(8,31,33,34,35,36)$. The studies of Lepschy and coworkers (8) and Abelson and coworkers (36) present the most accurate estimate of intestinal transit time by ACTH or $3 \mathrm{H}$-corticosterone injection in rats of different strains, finding a delay time between blood and faecal hormonal levels of $12-18 \mathrm{~h}$. For the predator odour test, we collected the faecal samples after $6-8 \mathrm{~h}$ following the end of the stress exposure. Thus, the FCM levels found are most likely to represent only the early hormonal secretion increase and not the actual peak concentration that can be assessed only after a longer time. This means that the EIA kit used is sensitive enough to reveal just a slight increase of FCM levels. 
Thus, both the adopted challenge events gave a biological validation of our EIA kit and proved the validity of the individual faecal sampling in male and female rats housed in social cages. To our knowledge, no other studies utilise a handling time for faecal collection as short as our sampling method. Recently, Frynta and collaborators (37) described a method that allows to collect faeces belonging to a single animal even in social conditions. They used a cage with partition in which an animal could be separated but continue to have visual, auditory and olfactory contacts with the other animals. However, this system requires a wire-mesh grid floor. It has been demonstrated that rats show a strong preference for solid floor compared with grid floor cage (38). Other studies show that housing rats on grid floor cages induce tactile hypersensitivity and nerve injury in the hind feet (39) and can also increase plasma level of corticosterone, blood pressure, heart rate and body temperature (40). Thus, this housing condition could alter faecal hormone metabolite assessment in rats.

Comparing both basal and stress FCM levels in the two challenge experiments, we found increased levels in the EE experiment.

This may be due to the fact that all the faecal samples of the EE experiment were collected in late morning, whereas all the samples of predator odour stress were collected in the afternoon. Based on FCM circadian level variations found in the isolated animals, higher FCM could be expected in the late morning samples with respect to afternoon faeces. As the two tests were performed on the same groups of animals, another reason could be that, when the second experiment (predator odour exposure) was performed, the animals were habituated to experimenters, as they had received more handling in comparison with the first experiment (EE exposure).

The results of FCM levels of the circadian rhythm experiment showed the expected physiological circadian variation of corticosterone secretion in male and female Wistar rats based on circadian variation of corticosterone secretion that can be observed in blood circulation (27), confirming that the kit was able to give reliable measurements.

Our study confirmed previous findings $(8,31,41)$ showing that males excreted more immunoreactive corticosterone metabolites in faeces than female rats, in all the tests performed, even if females generally release more corticosterone into circulation than males (27). The gender difference in faecal corticosterone excretion could be due to different factors. Female rats have approximately twice the amount of corticosteroid-binding-globulin activity, which inhibits steroid breakdown, with respect to males (42). In fact, only the unbound steroids are biologically active and can be metabolised. Moreover, due to differences in hormonal metabolism between the two sexes, females excrete a different set of corticosterone metabolites than males $(8,43)$. In addition, the antibody used in our EIA kit is likely to detect corticosterone metabolites formed by males to a higher extent. A slight difference in the time course of excreted metabolites among sexes as showed by Lepschy and coworkers (8) cannot be excluded. Instead, it is possible to exclude sex differences in the route of excretion of glucocorticoid metabolites in rats (8), in contrast to findings from other rodent species (1).

In conclusion, the results of this study support the possibility to perform individual faecal corticosterone determination, leaving the rats in standard social cages without the need for animal isolation. These findings could encourage researchers to use non-invasive methods for hormonal evaluations in laboratory animal research.

\section{Declaration of interest}

The authors declare that there is no conflict of interest that could be perceived as prejudicing the impartiality of the research reported.

\section{Funding}

The work was funded by Fondazione Ethoikos. Carlo Cinque and Anna Rita Zuena were supported by Fondazione Ethoikos training grant.

\section{Acknowledgements}

The authors thank Ludovica Cervi for language revision. They are grateful to the two anonymous reviewers for their help in improving the manuscript.

\section{References}

1 Touma C, Sachser N, Möstl E \& Palme R. Effects of sex and time of day on metabolism and excretion of corticosterone in urine and feces of mice. General and Comparative Endocrinology 2003130 267-278. (https://doi.org/10.1016/S0016-6480(02)00620-2)

2 Watson SL, McCoy JG, Stavisky RC, Greer TF \& Hanbury D. Cortisol response to relocation stress in Garnett's bushbaby (Otolemur garnettii). Contemporary Topics in Laboratory Animal Science 200544 22-24.

3 Sheriff MJ, Palme R, Dantzer B, Palme R \& Boonstra R. Measuring stress in wildlife: techniques for quantifying glucocorticoids. Oecologia 2011166 869-887. (https://doi.org/10.1007/s00442-0111943-y)

4 Benhaiem S, Dehnhard M, Bonanni R, Hofer H, Goymann W, Eulenberger K \& East ML. Validation of an enzyme immunoassay for the measurement of faecal glucocorticoid metabolites in spotted hyenas (Crocuta crocuta). General and Comparative Endocrinology 2012 178 265-271. (https://doi.org/10.1016/j.ygcen.2012.05.006)

5 Meyer JS \& Hamel AF. Models of stress in nonhuman primates and their relevance for human psychopathology and endocrine dysfunction. ILAR Journal 201455 347-360. (https://doi.org/10.1093/ilar/ilu023)

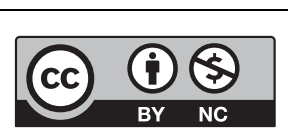

This work is licensed under a Creative Commons Attribution-NonCommercial 4.0 International License. 
6 Palme R, Rettenbacher S, Touma C, El-Bahr SM \& Mostl E. Stress hormones in mammals and birds comparative aspects regarding metabolism, excretion, and noninvasive measurement in fecal samples. Annals New York Academy Science 20051040 162-171. (https://doi.org/10.1196/annals.1327.021)

7 Pihl L \& Hau J. Faecal corticosterone and immunoglobulin A in young adult rats. Laboratory Animals 200337 166-171. (https://doi. org/10.1258/00236770360563822)

8 Lepschy M, Touma C, Hruby R \& Palme R. Non-invasive measurement of adrenocortical activity in male and female rats. Laboratory Animals 200741 372-387. (https://doi. org/10.1258/002367707781282730)

9 Christiansen S, Bouzinova EV, Palme R \& Wiborg O. Circadian activity of the hypothalamic-pituitary-adrenal axis is differentially affected in the rat chronic mild stress model of depression. Stress 201215 647-657. (https://doi.org/10.3109/10253890.2011.654370)

10 Cox C \& Hager R. Mothers do not show increased offspring avoidance and elevated corticosterone levels during weaning conflict in rats. PLOS ONE 201611 e0163195. (https://doi.org/10.1371/ journal.pone.0163195)

11 Barker TH, Bobrovskaya L, Howarth GS \& Whittaker AL. Female rats display fewer optimistic responses in a judgment bias test in the absence of a physiological stress response. Physiology and Behavior 2017173 124-131. (https://doi.org/10.1016/j.physbeh.2017.02.006)

12 Gomez-Sanchez EP \& Gomez-Sanchez CE. The effect of gonadectomy and aromatase inhibition on the excretion of 19-nordeoxycorticosterone in rats. Journal of Steroid Biochemistry and Molecular Biology 199139 185-188. (https://doi.org/10.1016/09600760(91)90061-9)

13 Heidbreder CA, Weiss IC, Domeney AM, Pryce C, Homberg J, Hedou G, Feldon J, Moran MC \& Nelson P. Behavioral, neurochemical and endocrinological characterization of the early social isolation syndrome. Neuroscience 2000100 749-768. (https://doi.org/10.1016/S0306-4522(00)00336-5)

14 Van Loo PLP, Van de Weerd HA, Van Zutphen LF \& Baumans V. Preference for social contact versus environmental enrichment in male laboratory mice. Laboratory Animals 200438 178-188. (https://doi.org/10.1258/002367704322968867)

15 Van Loo PLP, de Groot AC, Van Zutphen BFL \& Baumans V. Do male mice prefer or avoid each other's company? Influence of hierarchy, kinship and familiarity. Journal of Applied Animal Welfare Science 2001 4 91-103. (https://doi.org/10.1207/S15327604JAWS0402_1)

16 Beery AK \& Kaufer D. Stress, social behavior, and resilience: insights from rodents. Neurobiology of Stress 20151 116-127. (https://doi. org/10.1016/j.ynstr.2014.10.004)

17 Greco AM, Gambardella P, Sticchi R, D’Aponte D, Di Renzo G \& De Franciscis P. Effects of individual housing on circadian rhythms of adult rats. Physiology and Behavior 198945 363-366. (https://doi. org/10.1016/0031-9384(89)90141-8)

18 Cornale P, Macchi E, Renna M, Prola V, Perona G \& Mimosi A. Effect of cage type on fecal corticosterone concentration in buck rabbits during the reproductive cycle. Journal of Applied Animal Welfare Science 201619 90-96. (https://doi.org/10.1080/10888705.2 $015.1072468)$

19 Spulber S, Conti M, DuPont C, Raciti M, Bose R, Onishchenko N \& Ceccatelli S. Alterations in circadian entrainment precede the onset of depression-like behavior that does not respond to fluoxetine. Translational Psychiatry 20155 e603. (https://doi.org/10.1038/ tp.2015.94)

20 Melo I, Drews E, Zimmer A \& Bilkei-Gorzo A. Enkephalin knockout male mice are resistant to chronic mild stress. Genes Brain Behavior 201413 550-558. (https://doi.org/10.1111/gbb.12139)

21 Goymann W. Non-invasive monitoring of hormones in bird droppings: physiological validation, sampling, extraction, sex differences, and the influence of diet on hormone metabolite levels.
Annals New York Academy Science 20051046 35-53. (https://doi. org/10.1196/annals.1343.005)

22 Touma C \& Palme R. Measuring fecal glucocorticoid metabolites in mammals and birds: the importance of validation. Annals New York Academy Science 20051046 54-74. (https://doi.org/10.1196/ annals.1343.006)

23 Rosenzweig MR. Environmental complexity, cerebral change, and behavior. American Psychologist 199621 321-332. (https://doi. org/10.1037/h0023555)

24 Sztainberg Y \& Chen A. An environmental enrichment model for mice. Nature Protocols 20105 1535-1539. (https://doi.org/10.1038/ nprot.2010.114)

25 Moncek F, Duncko R, Johansson BB \& Jezova D. Effect of environmental enrichment on stress related systems in rats. Journal of Neuroendocrinology 200416 423-431. (https://doi.org/10.1111/j.13652826.2004.01173.x)

26 File SE, Zangrossi H Jr, Sanders FL \& Mabbutt PS. Dissociation between behavioral and corticosterone responses on repeated exposures to cat odor. Physiology and Behavior 199354 1109-1111. (https://doi.org/10.1016/0031-9384(93)90333-B)

27 Hutchinson EK, Avery AC \& Vandewoude S. Environmental enrichment during rearing alters corticosterone levels, thymocyte numbers, and aggression in female BALB/c mice. Journal of the American Association for Laboratory Animal Science 201251 18-24.

28 Vazdarjanova A, Cahill L \& McGaugh JL. Disrupting basolateral amygdala function impairs unconditioned freezing and avoidance in rats. European Journal of Neuroscience 200114 709-718. (https://doi. org/10.1046/j.0953-816x.2001.01696.x)

29 Takahashi LK, Nakashima BR, Hong H \& Watanabe K. The smell of danger: a behavioral and neural analysis of predator odor-induced fear. Neuroscience and Biobehavioral Reviews 200529 1157-1167. (https://doi.org/10.1016/j.neubiorev.2005.04.008)

30 Cavigelli SA, Monfort SL, Whitney TK, Mechref YS, Novotny M \& McClintock MK. Frequent serial fecal corticoid measures from rats reflect circadian and ovarian corticosterone rhythms. Journal of Endocrinology 2005184 153-163. (https://doi.org/10.1677/joe.1.05935)

31 Bamberg E, Palme R \& Meingassner JG. Excretion of corticosteroid metabolites in urine and faeces of rats. Laboratory Animals 200135 307-314. (https://doi.org/10.1258/0023677011911886)

32 Siswanto H, Hau J, Carlsson HE, Goldkuhl R \& Abelson KSP. Corticosterone concentrations in blood and excretion in faeces after ACTH administration in male Sprague-Dawley rats. In Vivo 200822 435-440.

33 Thanos PK, Cavigelli SA, Michaelides M, Olvet DM, Patel U, Diep MN \& Volkow ND. A non-invasive method for detecting the metabolic stress response in rodents: characterization and disruption of the circadian corticosterone rhythm. Physiological Research 200958 219-228.

34 Eriksson E, Royo F, Lyberg K, Carlsson HE \& Hau J. Effect of metabolic cage housing on immunoglobulin A and corticosterone excretion in faeces and urine of young male rats. Experimental Physiology 200489 427-433. (https://doi.org/10.1113/ expphysiol.2004.027656)

35 Abelson KS, Fard SS, Nyman J, Goldkuhl R \& Hau J. Distribution of $[3 \mathrm{H}]$-corticosterone in urine, feces and blood of male Sprague-Dawley rats after tail vein and jugular vein injections. In Vivo 200923 381-386.

36 Frynta D, Nováková M, Kutalová H, Palme R \& Sedlácek F. Apparatus for collection of fecal samples from undisturbed spiny mice (Acomys cahirinus) living in a complex social group. Journal of the American Association for Laboratory Animal Science 200948 196-201.

37 Manser CE, Morris TH \& Broom DM. An investigation into the effects of solid or grid cage flooring on the welfare of laboratory rats. Laboratory Animals 199529 353-363. (https://doi. org/10.1258/002367795780740023) http://www.endocrineconnections.org https://doi.org/10.1530/EC-17-0338
() 2018 The authors Published by Bioscientifica Ltd
This work is licensed under a Creative Commons Attribution-NonCommercial 4.0 International License. 
38 Mizisin AP, Kalichman MW, Garrett RS \& Dines KC. Tactile hyperesthesia, altered epidermal innervation and plantar nerve injury in the hindfeet of rats housed on wire grates. Brain Research 1998788 13-19. (https://doi.org/10.1016/S0006-8993(97)01474-1)

39 Krohn TC, Hansen AK \& Dragsted N. Telemetry as a method for measuring the impact of housing conditions on rat's welfare. Animal Welfare 200312 53-62.

40 Atkinson HC \& Waddell BJ. Circadian variation in basal plasma corticosterone and adrenocorticotropin in the rat: sexual dimorphism and changes across the estrous cycle. Endocrinology 1997138 3842-3848. (https://doi.org/10.1210/ endo.138.9.5395)
41 Cavigelli SA, Guhad FA, Ceballos RM, Whetzel CA, Nevalainen T, Lang CM \& Klein LC. Fecal corticoid metabolites in aged male and female rats after husbandry-related disturbances in the colony room. Journal of the American Association for Laboratory Animal Science 2006 45 17-21.

42 Gala RR \& Westphal U. Corticosteroid-binding globulin in the rat: studies on the sex difference. Endocrinology 196577 841-851. (https://doi.org/10.1210/endo-77-5-841)

43 Eriksson H \& Gustafsson J. Steroids in germfree and conventional rats: distribution and excretion of labeled pregnenolone and corticosterone in male and female rats. European Journal of Biochemistry 197015 132-139. (https://doi.org/10.1111/j.1432-1033.1970.tb00987.x)

Received in final form 18 December 2017

Accepted 4 January 2018

Accepted Preprint published online 4 January 2018 http://www.endocrineconnections.org https://doi.org/10.1530/EC-17-0338 (c) 2018 The authors Published by Bioscientifica Ltd

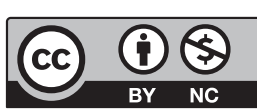

This work is licensed under a Creative Commons Attribution-NonCommercial 4.0 International License. 